\title{
COMPOSITION OPERATORS AND CLOSURES OF A CLASS OF MÖBIUS INVARIANT FUNCTION SPACES IN THE BLOCH SPACE
}

\section{LIXU ZHANG}

Abstract. Closures of a class of Möbius invariant function spaces in the Bloch space are investigated in this paper. Moreover, the boundedness and compactness of composition operators from the Bloch space to closures of such Möbius invariant space in the Bloch space are characterized.

Mathematics subject classification (2010): 30H30, 30H99, 47B33.

Keywords and phrases: Möbius invariant space, Bloch space, closure, composition operator.

\section{REFERENCES}

[1] J. Anderson, Bloch functions: the basic theory, Operators and function theorey (Lancaster, 1984), 1-17, NATO Adv. Sci. Inst. Ser. C Math. Phys. Sci. 153, Reidel, Dordrechet, 1985.

[2] J. Anderson, J. Clunie And Ch. Pommerenke, On Bloch functions and normal functions, J. Reine Angew. Math., 270 (1974), 12-37.

[3] J. Arazy, S. Fisher And J. Peetre, Möbius invariant function spaces, J. Reine Angew. Math., 363 (1985), 110-145.

[4] R. Aulaskari AND R. ZHAO, Composition operators and closures of some Möbius invariant spaces in the Bloch space, Math. Scand., 107 (2010), 139-149.

[5] G. BAO AND N. GöĞÜş, On the closures of Dirichlet type spaces in the Bloch space, Complex Anal. Oper. Theory, 13 (2019), 45-59.

[6] C. C. Cowen and B. D. MacCluer, Composition Operators on Spaces of Analytic Functions, CRC Press, Boca Raton, FL, 1995.

[7] P. Duren, Theory of $H^{p}$ Spaces, Academic Press, New York, 1970.

[8] P. Galanopoulos, On $\mathscr{B}_{\log }$ to $Q_{\log }^{p}$ pullbacks, J. Math. Anal. Appl., 337 (2008), 712-725.

[9] P. Galanopoulos, N. Monreal Galán and J. Pau, Closure of Hardy spaces in the Bloch space, J. Math. Anal. Appl., 429 (2015), 1214-1221.

[10] J. Garnett, Bounded Analytic Functions, Springer, New York, 2007.

[11] P. Ghatage And D. Zheng, Analytic functions of bounded mean oscillation and the Bloch space, Integr. Equ. Oper. Theory, 17 (1993), 501-515.

[12] S. G. KRAntZ AND S. STević, On the iterated logarithmic Bloch space on the unit ball, Nonlinear Anal., TMA 71 (2009), 1772-1795.

[13] S. LI, Differences of generalized composition operators on the Bloch space, J. Math. Anal. Appl., 394 (2012), 706-711.

[14] S. LI AND S. STEVIĆ, Generalized composition operators on Zygmund spaces and Bloch type spaces, J. Math. Anal. Appl., 338 (2008), 1282-1295.

[15] S. Li AND S. STEvić, Composition followed by differentiation between $H^{\infty}$ and $\alpha$-Bloch spaces, Houston J. Math., 35, 1 (2009), 327-340.

[16] S. Li And S. STEVIĆ, Products of integral-type operators and composition operators between Blochtype spaces, J. Math. Anal. Appl., 349 (2009), 596-610.

[17] S. Li And S. STEvić, Products of composition and differentiation operators from Zygmund spaces to Bloch spaces and Bers spaces, Appl. Math. Comput., 217 (2010), 3144-3154.

[18] S. Li AND S. STEVIĆ, Generalized weighted composition operators from $\alpha$-Bloch spaces into weighted-type spaces, J. Inequal. Appl., Vol. 2015, Article No. 265, (2015), 12 pages. 
[19] X. LiU AND S. Li, Norm and essential norm of a weighted composition operator on the Bloch space, Integr. Equ. Oper. Theory, 87 (2017), 309-325.

[20] Z. Lou, Composition operators on Bloch type spaces, Analysis (Munich), 23 (2003), 81-95.

[21] Z. Lou AND W. CHEN, Distances from Bloch functions to $\mathscr{Q}_{K}$-type space, Integr. Equ. Oper. Theory, 67 (2010), 171-181.

[22] K. Madigan And A. Matheson, Compact composition operators on the Bloch space, Trans. Amer. Math. Soc., 347 (1995), 2679-2687.

[23] N. Monreal Galán And A. Nicolau, The closure of the Hardy space in the Bloch norm, Algebra i Analiz, 22 (2010), 75-81, translation in St. Petersburg Math. J., 22 (2011), 55-59.

[24] R. QIAN AND S. Li, Composition operators and closures of Dirichlet type spaces $\mathscr{D}_{\alpha}$ in the logarithmic Bloch space, Indag. Math., 29 (2018), 1432-1440.

[25] R. QIAn And S. Li, Composition operators and closures of Dirichlet type spaces $\mathscr{D}_{\mu}$ in Bloch type spaces, Anal. Math., 45, 1 (2019), 121-132.

[26] B. SEHBA And S. STEVić, On some product-type operators from Hardy-Orlicz and Bergman-Orlicz. spaces to weighted-type spaces, Appl. Math. Comput., 233C (2014), 565-581.

[27] S. STEVIĆ, Norm and essential norm of composition followed by differentiation from $\alpha$-Bloch spaces to $H_{\mu}^{\infty}$, Appl. Math. Comput., 207 (2009), 225-229.

[28] S. STEVIĆ, On an integral-type operator from logarithmic Bloch-type and mixed-norm spaces to Bloch-type spaces, Nonlinear Anal., TMA 71 (2009), 6323-6342.

[29] S. STEVić, Products of composition and differentiation operators on the weighted Bergman space, Bull. Belg. Math. Soc. Simon Stevin, 16 (2009), 623-635.

[30] S. STEVIĆ, Products of integral-type operators and composition operators from a mixed norm space to Bloch-type spaces, Siberian Math. J., 50 (2009), 726-736.

[31] S. STEVIĆ, Weighted differentiation composition operators from mixed-norm spaces to weighted-type spaces, Appl. Math. Comput., 211 (2009), 222-233.

[32] S. STEVIĆ, Composition followed by differentiation from $H^{\infty}$ and the Bloch space to $n$th weightedtype spaces on the unit disk, Appl. Math. Comput., 216 (2010), 3450-3458.

[33] S. STEVIć, Weighted differentiation composition operators from the mixed-norm space to the $n$th weighted-type space on the unit disk, Abstr. Appl. Anal., Vol. 2010, Article ID 246287, (2010), 15 pages.

[34] S. STEVIĆ, On an integral operator between Bloch-type spaces on the unit ball, Bull. Sci. Math., 134 (2010), 329-339.

[35] S. STEVIĆ, On operator $P_{\varphi}^{g}$ from the logarithmic Bloch-type space to the mixed-norm space on unit ball, Appl. Math. Comput., 215 (2010), 4248-4255.

[36] S. STEVIĆ, Essential norm of some extensions of the generalized composition operators between $k$ th weighted-type spaces, J. Inequal. Appl., Vol. 2017, Article No. 220, (2017), 13 pages.

[37] S. Stević, A. K. Sharma And A. Bhat, Products of multiplication composition and differentiation operators on weighted Bergman spaces, Appl. Math. Comput., 217 (2011), 8115-8125.

[38] M. TJAnI, Compact composition operators on some Möbius invariant Banach space, $\mathrm{PhD}$ dissertation, Michigan State University, 1996.

[39] M. TuAni, Distance of a Bloch function to the little Bloch space, Bull. Austral. Math. Soc., 74 (2006), 101-119.

[40] H. Wulan, D. Zheng AND K. ZHU, Compact composition operators on BMOA and the Bloch space, Proc. Amer. Math. Soc., 137 (2009), 3861-3868.

[41] W. XU, Distances from Bloch functions to some Möbius invariant spaces in the unit ball of $\mathbb{C}^{n}, \mathrm{~J}$. Funct. Spaces Appl., 7 (2009), 91-104.

[42] R. ZHAO, On a general family of function spaces, Ann Acad Sci Fenn Diss., 105 (1996).

[43] R. ZHAO, Distances from Bloch functions to some Möbius invariant spaces, Ann. Acad. Sci. Fenn. Math., 33 (2008), 303-313.

[44] R. ZHAO, Essential norms of composition operators between Bloch type spaces, Proc. Amer. Math. Soc., 138 (2010), 2537-2546.

[45] K. ZHU, Bloch type spaces of analytic functions, Rocky Mountain J. Math., 23 (1993), 1143-1177.

[46] K. ZHU, A class of Möbius invariant function spaces, Illinois J. Math., 51 (2007), 977-1002.

[47] K. ZHU, Operator Theory in Function Spaces, American Mathematical Society, Providence, RI, 2007. 